\section{Chandler's thrombi as agents for the assessment of anti-thrombotic drugs in vitro}

DAVID H. LAWSON, MARGARET M. HUTTON, AND GEORGE P. MCNICOL From the University Department of Medicine and Department of Haematology, Royal Infirmary, Glasgow

This paper reports the effect of a plasminogen activator (streptokinase), a fibrinolytic inhibitor (aminocaproic acid), and an inhibitor of platelet aggregation (VK774-Boehringer Ingleheim) on the lysis of thrombi formed in a Chandler tube (Chandler, 1958) from blood of normal subjects and from patients on long-term anticoagulant therapy.

Since controlled clinical trials of antithrombotic therapy are difficult to conduct, time-consuming, and expensive (Fletcher, 1969), it is suggested that the Chandler thrombus provides a suitable test system to predict potential efficacy of drugs suitable for therapeutic trial as 'antithrombotic' agents.

\section{Methods}

Artificial thrombi were made by the method of Chandler (1958) as modified by McNicol, Bain, Walker, Rifkind, and Douglas (1965). After washing each thrombus was weighed and transferred to a perfusion circuit consisting of a second Chandler's loop. Thrombi were rotated at $37^{\circ} \mathrm{C}$ for four hours Received for publication 5 February 1973. in this loop and the effect of various perfusion fluids upon the postperfusion weight of each thrombus was assessed. Perfusion fluids used were: (1) sodium chloride $(\mathrm{NaCl}) 0.9 \%$ solution; (2) streptokinase $200 \mathrm{NIH}$ units $/ \mathrm{ml}$; (3) aminocaproic acid $3.3 \times 10^{-3}$ moles; (4) streptokinase and aminocaproic acid combined in concentration similar to the above.

In a group of patients VK774, a potent inhibitor of platelet aggregation and adhesiveness (Slater, Turpie, Douglas, and McNicol, 1972), was added in a concentration of $10^{-3}$ moles to the blood used to make thrombi. Control thrombi were made from blood which had equivalent volumes of saline added to it. Platelet counts were performed on the supernatant fluids after thrombus formation was complete.

Blood was obtained from healthy volunteers and from patients who had received at least one year of anticoagulant therapy following a myocardial infarction. For the latter group age- and sex-matched post-infarct control subjects (not on anticoagulant therapy) were studied at the same time.

\section{Results}

Thrombi formed from blood of 11 normal subjects and then perfused with streptokinase for four hours sustained a significantly greater weight loss than did control thrombi from the same subjects perfused with saline $(P<0.005$, table I).

Four thrombi were formed from the blood of each of eight normal subjects and then one was perfused with streptokinase, one with streptokinase/aminocaproic acid, one with aminocaproic acid, and one with $\mathrm{NaCl}$. The mean reduction in thrombus weight was similar in those perfused with aminocaproic

\begin{tabular}{|c|c|c|c|c|}
\hline Perfusion Fluid & No. of Thrombi & Thrombus Weight (mg) & $\begin{array}{l}\text { Reduction in Thrombus } \\
\text { Weight (mg) }\end{array}$ & $\begin{array}{l}\text { Percentage Reduction in } \\
\text { Thrombus Weight }\end{array}$ \\
\hline $\begin{array}{l}\mathrm{SK} \\
\mathrm{NaCl}\end{array}$ & $\begin{array}{l}11 \\
11\end{array}$ & $\begin{array}{l}210 \pm 30^{1} \\
220 \pm 40 \\
(P>0 \cdot 3)\end{array}$ & $\begin{array}{l}70 \pm 10^{1} \\
30 \pm 6 \\
(P<0.005)\end{array}$ & $\begin{array}{l}36 \cdot 2+2 \cdot 1^{1} \\
16 \cdot 2+2 \cdot 1 \\
(P<0 \cdot 0005)\end{array}$ \\
\hline
\end{tabular}

Table I Comparison of effect of streptokinase $(\mathrm{SK})$ and saline $(\mathrm{NaCl})$ perfusions of preformed thrombi from normal volunteer subjects

${ }^{1}$ Results expressed as mean $\div$ SEM

\begin{tabular}{|c|c|c|c|c|}
\hline Perfusion Fluid & No. of Thrombi & Thrombus Weight (mg) & $\begin{array}{l}\text { Reduction in Thrombus } \\
\text { Weight }(\mathrm{mg})\end{array}$ & $\begin{array}{l}\text { Percentage Reduction in } \\
\text { Thrombus Weight }\end{array}$ \\
\hline $\begin{array}{l}\text { SK } \\
\mathrm{NaCl} \\
\text { ACA } \\
\text { SK/ACA }\end{array}$ & $\begin{array}{l}8 \\
8 \\
8 \\
8\end{array}$ & $\begin{array}{l}310 \pm 50^{1} \\
310 \pm 60 \\
320 \pm 50 \\
300 \pm 50\end{array}$ & $\begin{array}{l}118 \pm 21 \\
40 \pm 8 \\
47 \pm 12 \\
46 \pm 14\end{array}$ & $\begin{array}{l}39.9 \pm 3.4 \\
14.3 \pm 2.4 \\
13.7 \div 1.6 \\
15.9 \pm 3.6\end{array}$ \\
\hline
\end{tabular}

Table II Comparison of effect of streptokinase $(\mathrm{SK})$, saline $(\mathrm{NaCl})$, aminocaproic acid $(\mathrm{ACA})$, or streptokinase with aminocaproic acid $(S K / A C A)$ perfusions of preformed thrombi from normal volunteers

${ }^{1}$ Results expressed as mean $\div$ SEM 


\begin{tabular}{|c|c|c|c|c|c|}
\hline Patients & Perfusion Fluid & No. of Thrombi & $\begin{array}{l}\text { Thrombus Weight } \\
\text { (mg) }\end{array}$ & $\begin{array}{l}\text { Reduction in } \\
\text { Thrombus Weight } \\
(\mathrm{mg})\end{array}$ & $\begin{array}{l}\text { Percentage Reduction } \\
\text { in Thrombus Weight }\end{array}$ \\
\hline $\begin{array}{l}\text { Anticoagulated } \\
\text { Non-anticoagulated }\end{array}$ & $\begin{array}{l}\text { SK } \\
\text { SK }\end{array}$ & $\begin{array}{l}15 \\
15\end{array}$ & $\begin{array}{l}370 \pm 50^{1} \\
280 \pm 30 \\
(P<0.05)\end{array}$ & $\begin{array}{l}188 \pm 27 \\
138 \pm 22 \\
(P<0.05)\end{array}$ & $\begin{array}{l}45 \cdot 0 \pm 3 \cdot 2 \\
45 \cdot 5 \pm 3 \cdot 1 \\
(P>0 \cdot 3)\end{array}$ \\
\hline
\end{tabular}

Table III Effect of streptokinase (SK) perfusions of thrombi formed from blood of anticoagulated and nonanticoagulated patients with history of myocardial infarction

${ }^{1}$ Results expressed as mean \pm SEM

\begin{tabular}{|c|c|c|c|c|c|c|}
\hline $\begin{array}{l}\text { Thrombi Formed } \\
\text { with }\end{array}$ & $\begin{array}{l}\text { Thrombi Perfused } \\
\text { with }\end{array}$ & No. of Thrombi & $\begin{array}{l}\text { Thrombus Weight } \\
\text { (mg) }\end{array}$ & $\begin{array}{l}\text { Supernatant Fluid } \\
\text { Platelet Count } \\
\left(\times 10^{3} \mathrm{c} \mathrm{mm}\right)\end{array}$ & $\begin{array}{l}\text { Reduction in } \\
\text { Thrombus Weight } \\
\text { (mg) }\end{array}$ & $\begin{array}{l}\text { Percentage Reduction } \\
\text { in Thrombus Weight }\end{array}$ \\
\hline $\begin{array}{l}\text { VK774 } \\
\mathrm{VK} 774 \\
\mathrm{NaCl}\end{array}$ & $\begin{array}{l}\text { NaCl } \\
\text { SK } \\
\text { SK }\end{array}$ & $\begin{array}{l}11 \\
11 \\
11\end{array}$ & $\begin{array}{l}540 \pm 70^{1} \\
510 \pm 40 \\
500 \pm 40 \\
N S\end{array}$ & $\begin{array}{l}77.0 \pm 7.6 \\
77.0 \pm 7 \cdot 7 \\
23.0 \pm 2.3 \\
(P<0.001)\end{array}$ & $\begin{array}{l}12 \cdot 7 \pm 3 \cdot 3 \\
24 \cdot 9 \pm 3 \cdot 1 \\
20 \cdot 3 \pm 2 \cdot 7\end{array}$ & $\begin{array}{l}22 \cdot 5 \pm 4 \cdot 5 \\
48.8 \pm 3 \cdot 5 \\
40.6 \pm 4.4\end{array}$ \\
\hline
\end{tabular}

Table IV Effect of inhibitor of platelet aggregation (VK774) on lysis of thrombi by streptokinase (SK) and saline $(\mathrm{NaCl})$

${ }^{1}$ Results expressed as mean \pm SEM

acid and $\mathrm{NaCl}$. Thrombi perfused with streptokinase sustained a significantly greater weight loss $(\mathrm{P}<0.01)$ than those perfused with $\mathrm{NaCl}$ and this effect was inhibited by the addition of aminocaproic acid (group streptokinase/aminocaproic acid, table II).

The effect of anticoagulant therapy on thrombus formation is shown in table III. Thrombi from anticoagulated patients were significantly heavier than control thrombi $(P<0.05)$; however, the response to perfusion with streptokinase was similar in the two groups.

The addition of VK774 to blood of normal subjects before thrombus formation did not affect the weight of the subsequent thrombus and the effect of streptokinase on such thrombi was similar to that observed previously. The mean platelet count of the supernatant fluid was significantly higher in the VK774 group when compared to control thrombi (P $<0.001$, table IV).

\section{Comment}

These experiments demonstrate the thrombolytic effect in vitro of streptokinase on Chandler's thrombi by using a simple loop circulation and assessing the lysis by recording thrombus weight loss.
This effect was completely inhibited by the addition of aminocaproic acid. The system avoids the use of radioactive fibrinogen and permits free perfusion of thrombi in a circuit thus preventing their mechanical disruption against the wire basket previously used in this laboratory (McNicol et al, 1965).

The system is sensitive enough to assess the effect of inhibitors of platelet aggregation such as VK774 and shows the resulting thrombi to be normally sensitive to the lytic effect of streptokinase.

The results indicate that the simple Chandler's tube model may have general applicability for the screening in vitro of substances with potential therapeutic application as thrombolytic agents.

\section{References}

Chandler, A. B. (1958). In vitro thrombotic coagulation of the blood; a method for producing a thrombus. Lab. Invest., 7 $110-114$

Fletcher, A. P. (1969). Thrombolytic agents. In Thrombosis, edited by S. Sherry, K. M. Brinkhous, E. Genton, and J. M. Stengle, pp. 710-723. National Academy of Science, Washington, D.C.

McNicol, G. P., Bain, W. H., Walker F., Rifkind, B. M., and Douglas, A. S. (1965). Thrombolysis studied in an artificial circulation. Lancet, 1, 838-843.

Slater, S. D., Turpie, A. G. G., Douglas, A. S., and McNicol, G. P. (1972). Effect in vitro on platelet function of two compounds developed from the pyrimido-pyrimidines. J. clin. Path., 25, 427-432. 